University of Nebraska - Lincoln

DigitalCommons@University of Nebraska - Lincoln

Mechanical \& Materials Engineering Faculty

Publications

Mechanical \& Materials Engineering

Department of

10-10-2001

\title{
Fabrication of 2- and 3-Dimensional Nanostructures
}

Hong Jiang

University of Nebraska-Lincoln

Camelia N. Borca

Bo Xu

Brian W. Robertson

University of Nebraska-Lincoln, brobertson1@unl.edu

Follow this and additional works at: https://digitalcommons.unl.edu/mechengfacpub

Part of the Mechanical Engineering Commons

Jiang, Hong; Borca, Camelia N.; Xu, Bo; and Robertson, Brian W., "Fabrication of 2- and 3-Dimensional Nanostructures" (2001). Mechanical \& Materials Engineering Faculty Publications. 1.

https://digitalcommons.unl.edu/mechengfacpub/1

This Article is brought to you for free and open access by the Mechanical \& Materials Engineering, Department of at DigitalCommons@University of Nebraska - Lincoln. It has been accepted for inclusion in Mechanical \& Materials Engineering Faculty Publications by an authorized administrator of DigitalCommons@University of Nebraska Lincoln. 
International Journal of Modern Physics B, Vol. 15, Nos. 24 \& 25 (2001) 3207-3213

(c) World Scientific Publishing Company. Used by permission.

\title{
Fabrication of 2-and 3-Dimensional Nanostructures
}

\author{
Hong Jiang \\ Department of MechanicalEngineering and the Center for Materials Research and Analysis, \\ Walter Scott Engineering Center, University of Nebraska, Lincoln, Nebraska 68588-0656 \\ (hjiang1@unl.edu)
}

Camelia N. Borca

Department of Physics and Astronomy and the Center for Materials Research and Analysis, Behlen Laboratory of Physics, University of Nebraska, Lincoln, Nebraska 68588-0111

(camelia.borca@epfl.ch)

\section{Bo Xu}

Department of Physics and Astronomy and the Center for Materials Research and Analysis, Behlen Laboratory of Physics, University of Nebraska, Lincoln, Nebraska 68588-0111

\section{Brian W. Robertson}

Department of Mechanical Engineering and the Center forMaterials Research and Analysis, Walter Scott Engineering Center, University of Nebraska, Lincoln, Nebraska 68588-0656

(brobertson1@unl.edu)

Received September 8, 2000

\begin{abstract}
Amongst tools for fabricating periodic and aperiodic nanostructures and nanodevices, electron beam-induced organometallic chemical vapor deposition (E-OMCVD) offers a highly flexible and controllable one-step deposition process. E-OMCVD enables maskless fabrication of nanoscale research and custom structures that have least dimensions near or below $10 \mathrm{~nm}$-a scale at which other methods prove difficult or costly. Using the focused electron beamina modified HB501 field-emission scanning transmission electron microscope(STEM), pads and wires with uniform thickness and well-defined shapes have been defined and deposited. Although conditions for fabricating the smallest deposits have not yet been optimized, the edge acuity (sharpness) of the deposits is consistently as low as $4 \mathrm{~nm}$ or less and the corresponding smallest wire width is $8 \mathrm{~nm}$. Under different deposition conditions, three-dimensional open structured nanonetworks have been fabricated. Results of an investigation of E-OMCVD parameters are presented for the metallocene compound, nickelocene $\left(\mathrm{Ni}\left(\mathrm{C}_{5} \mathrm{H}_{5}\right)_{2}\right)$, as source organometallic.
\end{abstract}

\section{Introduction}

Nanostructures have become increasingly attractive in recent years, both technologically and scientifically, for their novel electronic and magnetic properties [1-4]. As their dimensions shrink below $100 \mathrm{~nm}$, however, the fabrication of precisely controlled structures becomes challenging. Many nanofabrication techniques have been developed and investigated such as electron beam lithography [5-7], focused ion beam techniques [8, 9], electrodeposition [10-12], self-organization [13-15] and chemical synthesis [16]. Each of these techniques has some drawback, such as surface composition modification, ion damage, complexity of the fabrication process, restriction to only certain shapes, or limitation to periodic but not mixed-shape structures.

Electron beam-induced organometallic chemical vapor deposition (E-OMCVD) is a single-step process in which different materials could be deposited sequentially in one machine without removing the substrate from the vacuum system. No contact with fluids or coating of the substrate is required in the process, no energetic ions bombard the surface, and vacuum to atmosphere transfers are almost eliminated. There is therefore less likelihood of surface modification during feature deposition. The E-OMCVD process involves introducing organometallic source vapor onto the substrate and irradiating the substrate 
with an electron beam only where deposits are to be created. The adsorbed organometallic molecules decompose following direct or indirect energy transfer from the primary electrons. If the source compound and substrate temperature are selected correctly, the metal atoms will be deposited in the beam irradiated region and the desorbed ligands and unirradiated source compound may then be pumped out cleanly. The potential for accurate control of the shape and position of the electron beam allows the precise deposition of any required shape of feature at any location. The technique is applicable to research and custom fabrication and to interconnect repair. For extension to commercial manufacturing, projection methods based, for example, on the SCALPEL approach developed by Berger and colleagues $[17,18]$ are appropriate for high throughput E-OMCVD.

In our previous work, nickelocene $\left(\mathrm{Ni}\left(\mathrm{C}_{5} \mathrm{H}_{5}\right)_{2}\right)$ has been studied as a source compound for radiation induced chemical vapor deposition [21] and is recognized as meeting the criteria for selective area chemical vapor deposition source compounds.

In this study, electron beam induced chemical vapor deposition is investigated as an approach for nanostructure fabrication from nickelocene as the source organometallic. The resulting structures are characterized and the effects of substrate temperature, electron dose and organometallic partial pressure on the structure of deposits are elucidated. The structures are shown to be readily controlled by suitable selection of deposition conditions.

\section{Experimental}

The fabrication of nanostructures was conducted in a modified VG HB501 field emission scanning transmission electron microscope (STEM). A base pressure near $10^{-9}$ torr was normal in the specimen chamber, which was modified to allow controlled introduction of source gas to the substrate surface.

The deposition of nanoscale features was performed by scanning a focused electron beam with probe size of near one nanometer and electron energy of $100 \mathrm{keV}$ across a $10 \mathrm{~nm}$ thick carbon while introducing nickelocene $\left(\mathrm{Ni}\left(\mathrm{C}_{5} \mathrm{H}_{5}\right)_{2}\right)$ as the source organometallic.

The structure analysis of the resulting features was performed in the VG HB501 STEM and in a JEOL 2010 high-resolution transmission electron microscope. X-ray photoemission spectroscopy was performed in an x-ray photoemission spectroscope (XPS) using $\mathrm{Mg} \mathrm{Ka}_{12}$ x-radiation and spectra were acquired with a large hemispherical electron energy analyzer from Physical Electronics (PHI Model 10360 Precision Energy Analyzer).

\section{Results and discussion}

Examples of the pads and lines routinely obtained by E-OMCVD are shown in Figure 1, which contains two annular dark field images of the depositions obtained at nickelocene partial pressure $6 \times 10^{-8}$ torr and substrate temperature $-68^{\circ} \mathrm{C}$. The image intensity in annular dark field images depends on the thickness and atomic number of the material. It can be seen from Figure 1 that the thickness of the deposits and the width of the lines are highly uniform. The spatial resolution is less than $4 \mathrm{~nm}$. The highly selective nature of the deposition is clearly demonstrated by the lack of deposit outside the regions scanned by the electron beam.

Figure 2 is a high-resolution TEM image of a deposit fabricated at substrate temperature $-58^{\circ} \mathrm{C}$ and nickelocene partial pressure $5 \times 10^{-8}$ torr. Lattice fringes can be seen in the enlarged part located in the upper right comer of the figure. The lattice fringe spacing of $2.06 \AA \pm 0.04$ corresponds closely to the interplanar distance $2.03 \AA$ of $\{111\}$ planes in bulk pure nickel. The microstructure of the deposit 
is composed of crystalline grains of a few nanometers in diameter embedded in an amorphous matrix.

X-ray photoemission spectroscopy of deposits fabricated at substrate temperature $-86^{\circ} \mathrm{C}$ and nickelocene partial pressure $1.5 \times 10^{-7}$ torr yielded the spectrum shown in figure 3 . The broad peak centered near $855 \mathrm{eV}$ lies close to $\mathrm{Ni} 2 \mathrm{p}^{3 / 2}$ which occurs at $852.7 \mathrm{eV}$. The quantity of the deposited material is too small for x-ray photoemission to detect all the phases in the deposit. However, nickel appears largely to be present in one nickelrich phase.
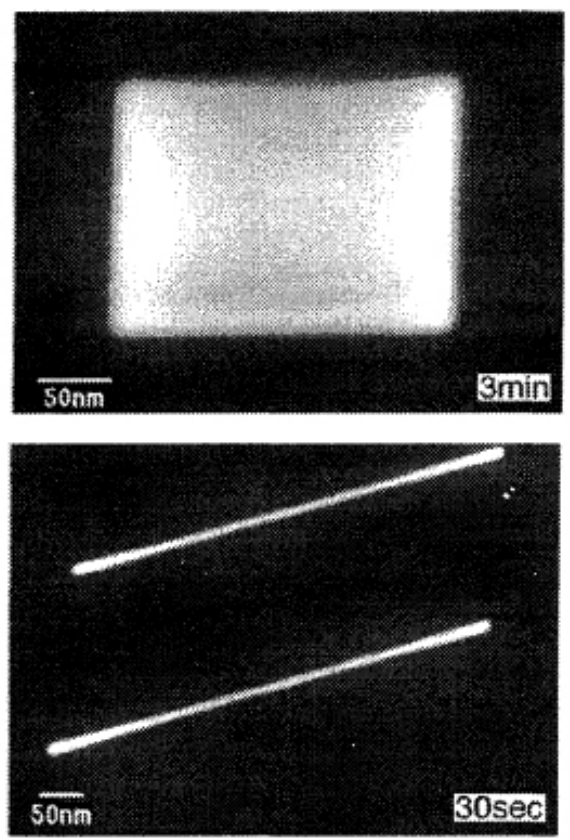

Figure 1. Annular dark field STEM images of results of deposition at partial pressure $6 \times 10^{-8}$ torr and substrate temperature $-68^{\circ} \mathrm{C}$.

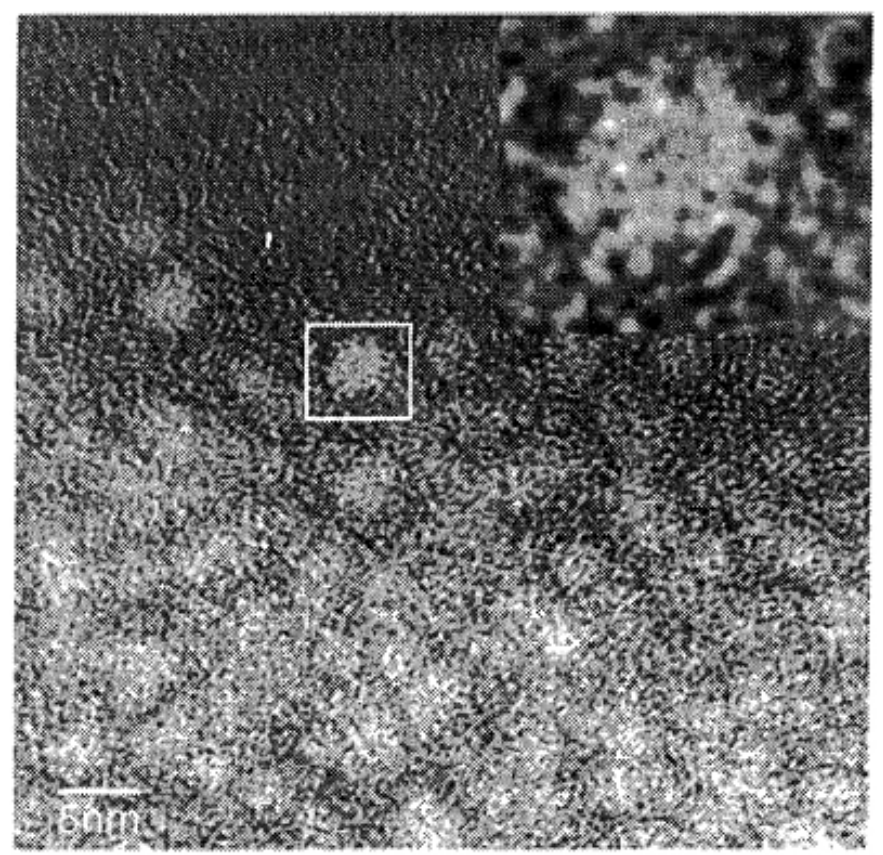

Figure 2. High resolution TEM image of a deposit at nickelocene partial pressure $5 \times 10^{-8}$ torr and substrate temperature $-58^{\circ} \mathrm{C}$.

Experiments have shown that the deposition results strongly depend on deposition parameters, amongst which the substrate temperature and the organometallic partial pressure during deposition appear to be the most significant process variables. A broad range (Figure 4) of deposit morphologies result from different temperatures and organometallic partial pressures. The deposits in figures 4 (a) and (b) are both uniform in thickness and smooth on surface although they were deposited at quite different substrate temperatures $\left(25^{\circ} \mathrm{C}\right.$ and $-68^{\circ} \mathrm{C}$, respectively). Experiments showed that uniform deposits can be achieved in a broad temperature range. The structure of the deposits is different at a lower temperature, as can be seen in figure 4 (c) and (d). Substrate temperatures during deposition were $-86^{\circ} \mathrm{C}$ for 4 (c) and $-103^{\circ} \mathrm{C}$ for 4 (d). The deposits in figure 4 (c) and (d) have a 3-dimensional open porous structure. By comparing partial pressures of nickelocene during deposition $\left(\mathrm{P}_{\mathrm{d}}\right)$ with equilibrium vapor pressures of nickelocene $\left(\mathrm{P}_{\mathrm{v}}\right)$ at the corresponding substrate temperatures (see Table 1 ), it is found that the formation of a uniform structure or a 3-dimensional open structure strongly depends on the ratio of partial pressures of nickelocene during deposition to equilibrium vapor pressures of nickel- 
ocene at the corresponding substrate temperatures. Vapor pressures listed in table 1 are estimated from Clausius-Clapeyron equation [22] using published vapor pressure data for nickelocene [23]. As listed in Table 1, the partial pressures of nickelocene during fabrication of the deposits in Figure 4 (a) $(3 \mathrm{x}$ $10^{-6}$ torr $)$ and 4 (b) $\left(6 \times 10^{-8}\right.$ torr) are below the equilibrium vapor pressures of nickelocene at the corres-

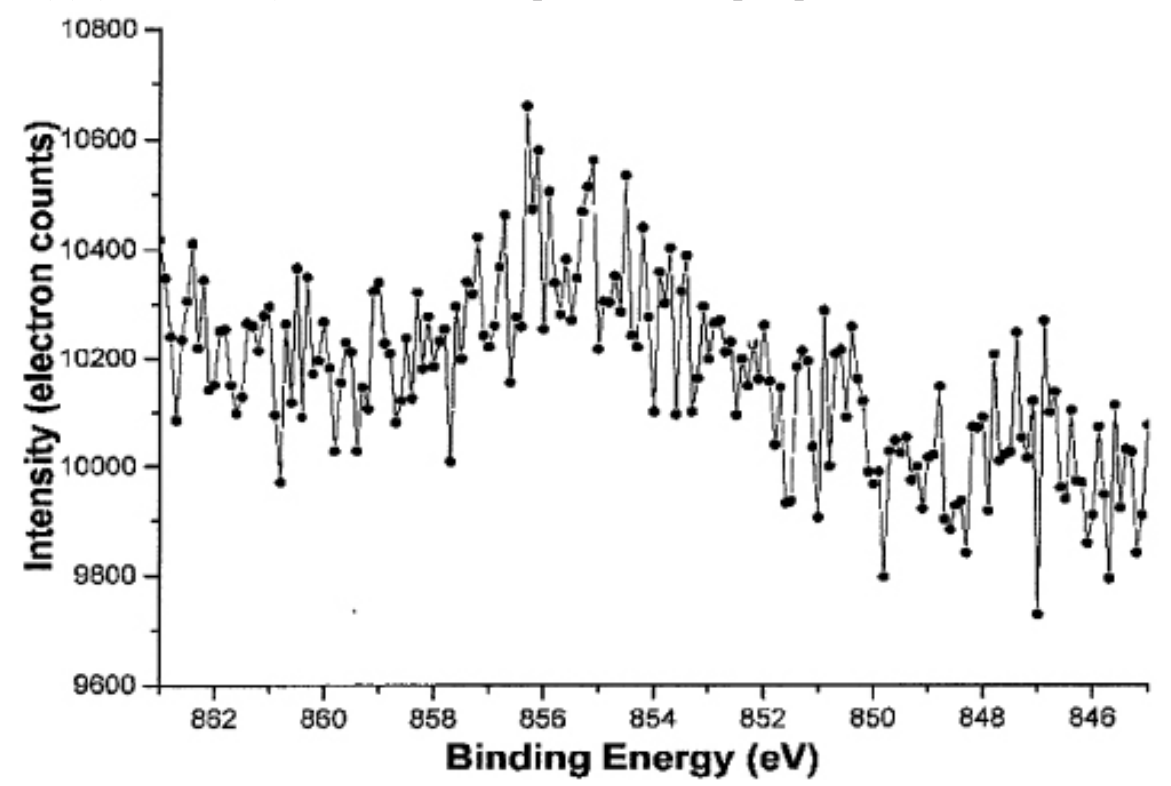

Figure 3. X-ray photoemission spectrum of deposits formed at nickelocene partial pressure of $1.5 \times 10^{-7}$ torr and substrate temperature of $-86^{\circ} \mathrm{C}$.

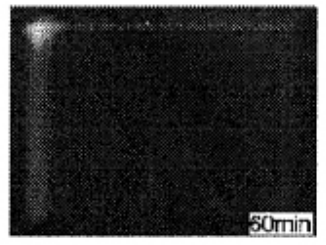

a)

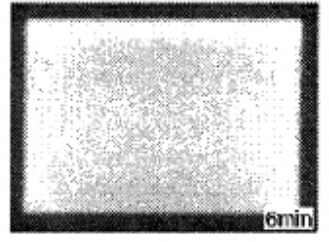

b)

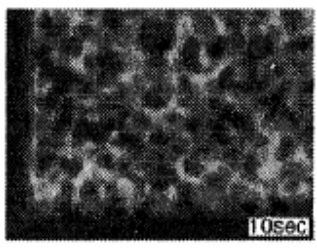

c)

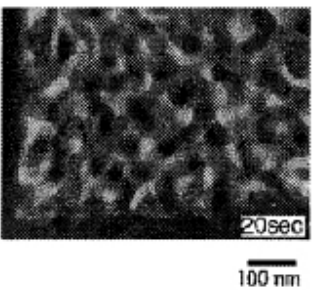

d)

Figure 4. Annular dark-field STEM images of material deposited under different conditions of nickelocene partial pressure and substrate temperatures: a) $\mathrm{T}_{\text {sub }}=25^{\circ} \mathrm{C}, \mathrm{P}_{\mathrm{OM}}=3 \times 10^{-6}$ torr. b) $\mathrm{T}_{\text {sub }}=-68^{\circ} \mathrm{C}, \mathrm{P}_{\mathrm{OM}}=6 \times 10^{-8}$ torr. c) $\mathrm{T}_{\text {sub }}$ $=-85^{\circ} \mathrm{C}, \mathrm{P}_{\mathrm{OM}}=5 \times 10^{-8}$ torr. d) $\mathrm{T}_{\text {sub }}=-103^{\circ} \mathrm{C}, \mathrm{P}_{\mathrm{OM}}=3 \times 10^{-8}$ torr.

ponding substrate temperatures equilibrium vapor pressures of nickelocene at the corresponding substrate temperatures $\left(1.7 \times 10^{-2}\right.$ torr at $25^{\circ} \mathrm{C}$ and $9.2 \times 10^{-8}$ torr at $\left.-68^{\circ} \mathrm{C}\right)$. The deposits are two-dimensional and uniform. For the deposits in Figure 4 (c) and 4 (d), the partial pressures of nickelocene during deposition ( $5 \times 10^{-8}$ torr and $3 \times 10^{-8}$ torr, respectively) are above vapor pressures of nickelocene at the corresponding temperatures $\left(2.7 \times 10^{-9}\right.$ torr at $-85^{\circ} \mathrm{C}$ and $3.1 \times 10^{-11}$ torr at $\left.-103^{\circ} \mathrm{C}\right)$. Three-dimensional nanonetworks are obtained in this condition. From such depositions, it can be concluded that the ratio of partial pressure to vapor pressure of nickelocene at the deposition temperature is a critical parameter for the control of the structure of deposits. Uniform, two-dimensional deposits can be achieved when the ratio is less than one. Three-dimensional nanonetworks can be obtained when the ratio is larger than one. Further details of investigation of the mechanism of the formation of the two different kinds of structures can be found in reference [24]. 
Table 1. Equilibrium vapor pressures $\left(\mathrm{P}_{\mathrm{v}}\right)$ of nickelocene at different temperatures (Vapor pressures are estimated from Clausius-Clapeyron equation [22] using published vapor pressure data of nickelocene [23]) and nickelocene partial pressures $\left(\mathrm{P}_{\mathrm{d}}\right)$ used in the depositions.

\begin{tabular}{c|c|c}
\hline Substrate temperature $\left({ }^{\circ} \mathrm{C}\right)$ & Equilibrium vapor pressure $\left(\mathrm{P}_{\mathrm{v}) \text { (torr) }}\right.$ & Deposition partial presure $\left(\mathrm{P}_{\mathrm{d}) \text { (torr) }}\right.$ \\
\hline 25 & $1.7 \times 10^{-2}$ & $3 \times 10^{-6}$ \\
-68 & $9.2 \times 10^{-8}$ & $6 \times 10^{-8}$ \\
-85 & $2.7 \times 10^{-9}$ & $5 \times 10^{-8}$ \\
-103 & $3.1 \times 10^{-11}$ & $3 \times 10^{-8}$ \\
\hline
\end{tabular}

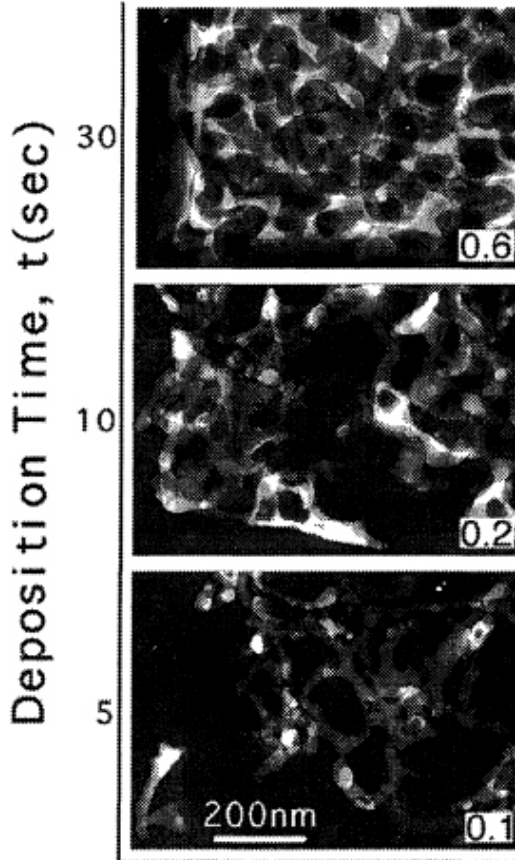

0.02
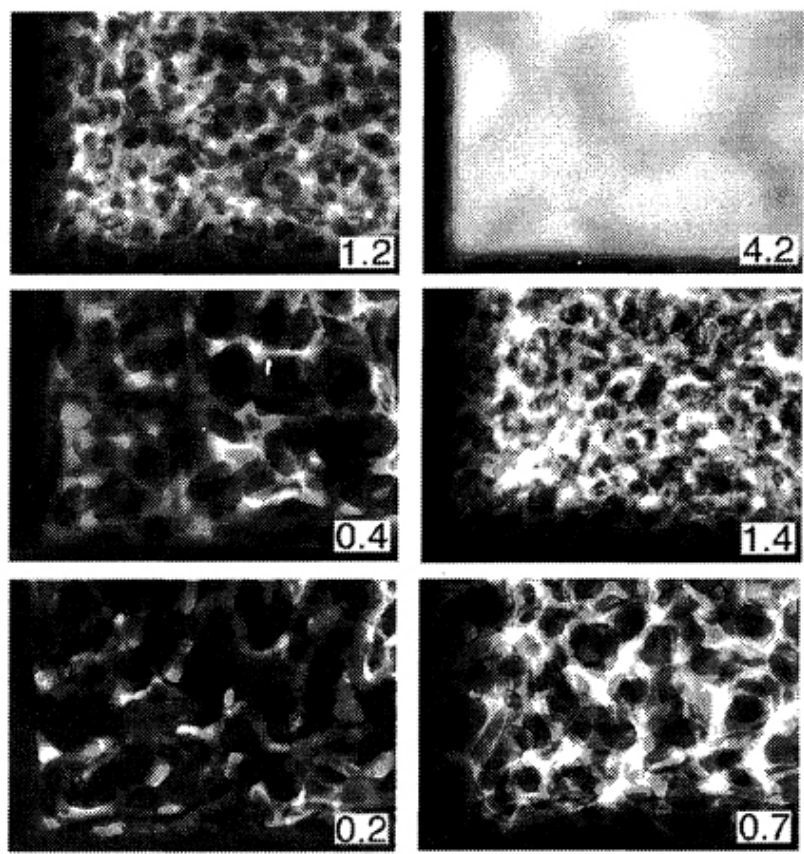

0.04

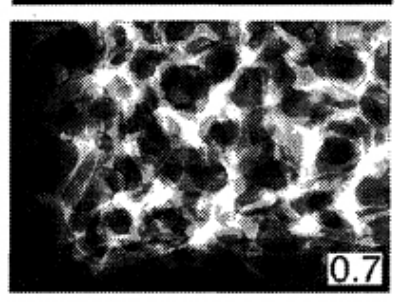

0.14

\section{Beam Current, I (nA)}

Figure 5. Annular dark-field STEM images of deposits with different electron dose at nickelocene partial pressure $5 \times 10^{-8}$ torr and substrate temperature $-85^{\circ} \mathrm{C}$. The electron dose in unit of (nA.sec) is marked at the right bottom corner for each deposit.

The series of STEM annular dark field images in Figure 5 indicates some of the range of open porous structured deposits obtainable with different deposition electron dose. The electron dose is marked in the lower right comer of each image in units of nAesec. For this series of depositions, the substrate temperature was $-85^{\circ} \mathrm{C}$ and nickelocene partial pressure was $5 \times 10^{-8}$ torr -much higher than nickelocene vapor pressure at $-85^{\circ} \mathrm{C}\left(2.7 \times 10^{-9}\right.$ torr $)$. Comparison of the three-dimensional open porous structures formed at such high partial pressure using similar electron dose indicates a similar quantity of deposited material and a similar structure. At low electron dose, deposited material forms a network with relatively large openings. As the electron dose is increased, the deposited material grows by forming more, smaller pore features of a three-dimensional network that is gradually filled completely or nearly so. Thus, by controlling the deposition conditions, three dimensional nanostructure networks 
can be fabricated.

\section{Conclusions}

Electron beam-induced organometallic chemical vapor deposition has been shown to be a successful technique for nanostructure fabrication. The ratio of the partial pressure of the source organometallic during deposition to the equilibrium vapor pressure of nickelocene at the substrate temperature is a critical value for controlling the structure of deposits. Two-dimensional high-resolution deposits can be achieved when this ratio is less than one. Three-dimensional open structured nanonetworks can be obtained when the ratio is larger than one. Deposits with edge sharpness (acuity) under $4 \mathrm{~nm}$ have been fabricated. Three-dimensional nanonetworks and hence nanocomposite materials can be fabricated by controlling deposition temperature, source compound, organometallic partial pressure and electron dose. We expect that nanocomposite materials could be created by switching to a different source organometallic during deposition, after a network has been constructed to an appropriate stage.

\section{Acknowledgment}

The authors are pleased to acknowledge discussion with P. A. Dowben and support for this work by the Office of Navy Research under contract N00014-96-1-0967 (Program Officer Kristl Hathaway).

\section{References}

1. H. Ahmed, Proc. IEEE 79 (1991) 1140.

2. S. J. Wind, Y. Taur, Y. Mii, D. J. Frank, H. -S. Wong, D. A. Buchanan, S. A. Rishton, J. J. Bucchignano, Y. Lii, K. A. Jenkins, Mat. Res. Soc. Symp. Proc. (1995) 179.

3. A. S. Edelstein, J. S. Murday, B. B. Rath, Progress in Mater. Sci. 42 (1997) 5.

4. F. J. Himpsel, J. E. Ortega, G. J. Mankey, R. F. Willis, Advances in Physics 47 (1998) 511.

5. C. R. K. Marrian, E. A. Dobisz, M. C. Peckerar, Proc. IEEE 79 (1991) 1149.

6. W. W. Molzen, A. N. Broers, J. J. Cuomo, J. M. E. Harper, R. B. Laibowitz, J. Vac. Sci. Technol. 16 (1979) 269.

7. N. Saitou, S. Okazaki, K. Nakamura, Solid State Tech. Nov. (1987) 65.

8. S. T. Davies, B. Khamsehpour, Vacuum 47 (1996) 455.

9. K. Barno, N. Takakura, N. Samoto, R. Shimizu, S. Namba, Jpn. J. Appl. Phys. 23 (1984) L293.

10. B. Doudin, J. E. Wegrowe, S. E. Gilbert, V. Scarani, D. Kelly, J. P. Meier, J-Hp Ansermet, IEEE Trans. on Magnetics 34 (1998) 968.

11. G. Fasol, K. Runge, Appl. Phys. Lett. 70 (1997) 2467.

12. D. Routkevitch, A. A. Tager, J. Haruyama, D. Almawlawi, M. Moskovits, J. M. Xu, IEEE Trans. on Electron Devices 43 (1996) 1646.

13. S. Sanguinetti, S. C. Fortina, A. Miotto, E. Grilli, M. Guzzi, M. Henini, A. Polimeni, L. Eaves, Thin Solid Films 336 (1998) 9.

14. M. Abdallah, J. Berbezier, P. Dawson, M. Serpentini, G. Bremond, B. Joyce, Thin Solid Films 336 (1998) 256.

15. V. A. Shchukin, D. Bimberg, Appl. Phys. A, Mater. Sci. E Proc. 67 (1998) 687.

16. L. Zhang, A. Manthiram, J. Appl. Phys. 80 (1996) 4534.

17. S. D. Berger, J. M. Gibson, R. M. Camarda, R. C. Farrow, H. A. Huggins, J. S. Kraus, J. A. Liddle, J. Vac. Sci. Technol. B 9 (1991) 2996. EB lithog.

18. J. A. Liddle, G. P. Watson, S. D. Berger, P. D. Miller, Jpn. J. Appl. Phys. 34 (1995) 6672. EB lithog. 
19. W. W. Pai, J. Zhang, J. F. Wendelken, R. J. Warmack, J. Vac. Sci. Technol. B 15 (1997) 785.

20. F. Thibaudau, J. R. Roche, F. Salvan, Appl. Phys. Lett. 64 (1994) 523.

21. D. Welipitiya, C. Waldfried, C. N. Borca, P. A. Dowben, N. M. Boag, H. Jiang, I. Gobulukoglu, B. W. Robertson, Surface Science 418 (1998) 466.

22. C. J. Adkins, Equilibrium Thermodynamics, McGraw-Hill, London, (1969).

23. A. G. Turnbull, Aust. J. Chem. 20 (1967) 2757.

24. H. Jiang, C. N. Borca, B. Xu, B. W. Robertson, submitted to Thin Solid Films. 